\title{
Pretest cuing after forgetting of a food-motivated maze task in rats: Synergistic action of context and reinforcement
}

\author{
BERNARD DEWEER \\ Centre National de la Recherche Scientifique, Gif sur Yvette, France
}

\begin{abstract}
It is now well known in animal studies that spontaneous forgetting, as well as performance decrements resulting from other sources, can be alleviated by means of pretest treatments. Several previous experiments have shown that reliable forgetting is observed after a 25-day training-totest interval on a relatively complex maze. This forgetting can be alleviated by pretest exposure to background stimuli in the experimental room. The effects of this treatment can be modulated by varying either the duration of the treatment or the length of the cuing-test interval. The purpose of the experiment presented here was twofold: (1) to demonstrate the multidimensionality of memories in our paradigm by comparing the effects of different reminder treatments, namely pretest access to the reinforcer and contextual cuing, and (2) to test the general hypothesis, formulated by Spear (1978, p. 418), that "the elicitation and retrieval of the target attribute of a memory depend on the arousal of a sufficient number or kind of the remaining attributes of this memory." The data showed that pretest food reinforcement had no significant effect on retention performance; that pretest contextual cuing did, in some precise conditions, alleviate forgetting; and that some combinations of context and reinforcement had what amounted to a synergistic action on retention performance.
\end{abstract}

It is now widely accepted that, in animals (see, e.g., Spear, 1978) as well as in humans (Bower, 1967), even the simplest memory must be considered multidimensional, that is, composed of a number of attributes or elements. These attributes are representations of the target memory (i.e., response-reinforcement contingencies in most animal studies), but also of events that preceded and followed the original training episode, of some contextual characteristics of the apparatus, and, more generally, of the external and internal ("motivational") training contexts. This idea is documented, in the domain of animal memory, by a number of data obtained from two different experimental strategies: pretest cuing and modifications of the situation between training and testing. Within each of these strategies, numerous examples illustrate this multidimensional nature of memories.

Thus, retention performance seems to be highly sensitive to a variety of modifications relative to the reinforcer (Capaldi, 1971; Spear, 1967), to the intra-apparatus (McAllister \& McAllister, 1971; Perkins \& Weyant, 1958; Riccio, Urda, \& Thomas, 1966; Steinman, 1967) or the extra-apparatus (Asratian, 1965; Deweer, 1985; Deweer \& Sara, 1985; Gordon, 1981) context, or even to the time of the day (Holloway, 1978; Holloway \& Wansley, 1973).

The author's temporary current address is: Veterans Administration Hospital, Medical Center, Department of Psychiatry (116), 3350 La Jolla Village Drive, San Diego, CA 92161. Requests for reprints should be sent to the author at Centre National de la Recherche Scientifique, Departement de Psychophysiologie, C.N.R.S.-L.P.N. 2, F 91190 Gif sur Yvette, France
As far as pretest cuing is concerned, and whatever the source of performance decrement (e.g., experimentally induced amnesia, interaction between conflictual memories, spontaneous long-term forgetting), numerous data also show that retrieval processes are highly labile and are sensitive to such diverse pretest cuing treatments as noncontingent exposure to the unconditioned stimulus (US) in a chamber that is quite different from the conditioning apparatus (e.g., Lewis, Misanin, \& Miller, 1968; Miller \& Springer, 1972; Spear \& Parsons, 1976), presentation of a positive reinforcer outside the training situation (Miller, Ott, Berk, \& Springer, 1974), and exposure to intra-apparatus (e.g., Hickis, Robles, \& Thomas, 1977; Miller et al., 1974; Sara, David-Remacle, \& Lefevre, 1975; Thomas, 1981) or extra-apparatus (Deweer, Sara, \& Hars, 1980; Gatti, Pais, \& Weeks, 1975) stimuli.

For the past several years, my colleagues and I have been using an appetitive maze task to study long-term retention and retrieval processes in the rat (Deweer et al., 1980; Sara, Deweer, \& Hars, 1976). We have consistently observed that a pretest treatment, consisting of a $90-\mathrm{sec}$ exposure to the background stimuli in the experimental room immediately prior to testing, alleviates the spontaneous forgetting observed in noncued animals after a long training-to-test interval. From these data, we inferred that representations relative to the experimental context were incorporated within the memory of the initial training. Some additional experiments (Deweer \& Sara, 1984) showed, moreover, that retention performance depends heavily upon the parameters of this kind of treatment. First, although a 90 -sec contextual cuing given immedi- 
ately before testing induces, from the first test trial, optimal performance levels (i.e., similar to the level attained at the end of training), the facilitative effects are only marginal when the same treatment is given $1 \mathrm{~h}$ or $24 \mathrm{~h}$ before testing. It is worth noting that a strict temporal contiguity between pretest cuing and testing is not necessary for the alleviation of spontaneous forgetting: Animals cued for $90 \mathrm{sec}$ at $5 \mathrm{~min}$ prior to testing, then replaced in their home cages for the cuing-test interval, also exhibit optimal performance levels on the first test trial (Dekeyne, Deweer, \& Sara, in press). Second, the duration of a contextual cuing episode immediately preceding testing can be a major determinant of retention performance. A 10 sec treatment has no detectable effect; 30 - or 90 -sec treatments are highly effective; a 300-sec treatment is less effective (see Deweer \& Sara, 1984).

The purpose of the experiment presented here was twofold: (1) to demonstrate the multidimensionality of memories in our paradigm by comparing the effects of several reminder treatments upon retention performance [as mentioned earlier, memories can be reactivated by means of several treatments, but direct comparisons of the effects of these treatments, in the same experimental conditions and in the same experiments, are still rare in the literature (with some notable exceptions; see, e.g., Moye \& Thomas, 1982)]; and (2) to test the general hypothesis, formulated by Spear (1978, p. 418), that "the elicitation and retrieval of the target attribute of a memory depend on the arousal of a sufficient number or kind of the remaining attributes of that memory."

To answer these questions, we compared the effects of two pretest treatments: those of a contextual cuing procedure, similar to that used in several previous experiments, and those of a more widely used "reminder" procedure, a pretest presentation, in another context, of the reinforcer used throughout pretraining and training.

\section{PILOT EXPERIMENT}

This direct comparison required an initial experiment to search, in our paradigm, for possible effects of reinforcement as reminder. Briefly, after learning the maze (see below, Main Experiment, Method), the animals were divided into five matched groups. Twenty-one animals were assigned to a "nonmanipulated" control group; as in previous experiments, these animals were carried from the colony room to the experimental room 25 days after the last training trial, and immediately placed into the startbox of the maze for testing. The animals assigned to the remaining groups were submitted to the following pretest treatments: they were placed, for $90 \mathrm{sec}$, in a cage, similar to the home cages, with food available. This cage was located in the colony room. For two of these groups, the available food was the same as that given every day in the home cages; for the two remaining groups, the available food was what had been specifically used as reinforcer throughout pretraining and training. In both conditions, the animals assigned to one group were given access to food immediately before being placed into the startbox of the maze for testing; the animals assigned to the remaining group were given access to food $1 \mathrm{~h}$ before testing, and spent the "reminder"--test interval in their home cages.

Between-group comparisons showed no significant differences among the five groups, whatever the retention index (i.e., run times, errors, and retracings; see below, Main Experiment). However, planned comparisons showed a nonsignificant tendency for fewer errors in animals given pretest access to the specific reinforcer than in animals given access to the daily food and in nonmanipulated control animals. In other words, these data suggested that although pretest access to daily food had negligible effects on error scores, pretest access to the specific reinforcer might somewhat alleviate spontaneous forgetting. For this reason, pretest access to the specific reinforcer in the colony room was used as a reminder treatment in the main experiment, which was, in part, a replication of this pilot study.

\section{MAIN EXPERIMENT}

The main experiment consisted of (1) a direct comparison of the effects of different pretest reminders (access to the reinforcer in the colony room and exposure to background stimuli in the experimental room) and (2) a test of the hypothesis that a pretest presentation of several elements noticed during training should have more facilitative effects on retention performance than the presentation of only one of these elements, since this procedure should increase the degree of similarity between the pretest situation and the representations relative to training (Tulving \& Thomson, 1973).

This experiment was built upon the basis of data from previous experiments, which had shown that (1) a pretest exposure to background stimuli in the experimental room enhances retention performance when given immediately prior to testing, but has only marginal effects when given $1 \mathrm{~h}$ before testing; (2) the duration of this reminder treatment can be a major determinant of its efficacy; (3) a 90 sec access to the reinforcer in the colony room has marginal effects on retention performance, even when it takes place immediately prior to testing (Pilot Experiment; Deweer \& Sara, 1985).

\section{Method}

Subjects

One hundred and twelve male Sprague-Dawley rats, obtained from IFFA-CREDO, France, served as subjects. They weighed $220 \mathrm{~g}$ on arrival in the laboratory and were housed, in pairs, in wire-mesh cages measuring $35 \times 21 \times 18 \mathrm{~cm}$. Eight days after arrival, they were placed on a food-deprivation schedule in which the daily rationgiven between 5 and 7 p.m. - was gradually reduced to $15 \mathrm{~g}$ (rat chow) over 4 days. This regimen was maintained (with some individual corrections) throughout the pretraining and training periods. Under these conditions, the animals weighed approximately $85 \%$ of their free-feeding weights at the end of the training period.

\footnotetext{
Apparatus

The linear maze consisted of six $50 \times 40 \times 35 \mathrm{~cm}$ units, with 10 $\mathrm{cm}$ openings between them. A $25 \times 25 \times 35 \mathrm{~cm}$ startbox was sepa-
} 
rated from the first unit by a sliding door. The goalbox, of the same dimensions as the startbox, could also be closed by a sliding door. The choice point, or stem of the $T$, was located $15 \mathrm{~cm}$ from the entrance of each unit. The transverse of the $T$ was $25 \mathrm{~cm}$ from the choice point. The barriers in each unit of the maze could be changed from one side to the other; the maze configuration was LRRLLR or RLLRRL, and the entire maze measured approximately $3 \mathrm{~m}$ in length. This apparatus was located in a room adjacent to the room in which the animals were housed. The major difference between the two rooms was lighting. The colony room was naturally lighted. The windows of the experimental room were covered with large black panels, and the room was illuminated by three $75-\mathrm{W}$ bulbs located $2.5 \mathrm{~m}$ above the maze. The air conditioning system was common to both rooms.

\section{Procedure}

The first 5 days comprised a pretraining period, during which the animals were habituated to the experimenter, the experimental conditions, and the maze. On Day 1, each rat was allowed to feed (0.2-g pellets) for one 20 -min period in a box resembling the startbox and goalbox of the maze. On Day 2, the rats, in gangs of 6 , were given $30 \mathrm{~min}$ free exploration of the entire maze, with the sliding doors open, the barriers removed, and food pellets available in the goalbox. On the following days, using only the last maze unit, 2 rats at a time (Day 3) and then individual rats were trained to enter the goalbox (the door of which was closed after the rat entered the goalbox on Day 5), where they were allowed to feed for $5 \mathrm{~min}$.

Training began on Day 8. Barriers were placed at the appropriate points, and the path was changed to its mirror configuration for every other rat. Each animal was carried from the colony room to the experimental room and placed into the startbox. The sliding door was then immediately opened, and the time it took for the rat to attain the goalbox and the number of errors and retracings were noted. An error was noted each time a rat entered a blind alley (rear paws beyond the stem of the T). Each error was followed either by a correction (i.e., choice of the other alley of the same unit) or by a retracing. A retracing was noted whenever a rat went back from one unit to the preceding one or ones. A retracing generally followed an error, but not necessarily; it could also be observed, for example, after hesitation at a choice point. When reaching the goalbox, the animal was allowed to feed for $2 \mathrm{~min}$ before being removed and returned to its home cage. There were five training trials with a $24-\mathrm{h}$ intertrial interval.

At the end of training, the animals were divided into eight matched groups on the basis of their mean performance on the last two training trials. Performance criteria were total time to run the maze, number of errors, and number of retracings. The animals were kept in their home cages with free access to food and water for the first part of the training-to-test interval. Seven days before retention testing, the gradual reduction in food was reintroduced as before pretraining. Fourteen animals were assigned to the nonmanipulated control group (Group C); the animals assigned to the remaining groups were given, before testing, a reminder treatment. For animals in Group $R_{0} 90$, this treatment was a 90 -sec exposure to background stimuli in the experimental room immediately prior to testing. Animals assigned to the six remaining groups were all subjected to a reminder treatment $1 \mathrm{~h}$ before testing; they spent the remindertest interval in their home cages (see Figure 1). The treatments were: a 90-sec exposure to background stimuli in the experimental room for Group $R_{1} 90$; a 180-sec exposure to background stimuli in the experimental room for Group $R_{1} 180$; a 90 -sec access to the reinforcer in the colony room for Group $F_{1} 90$; a 180-sec access to the reinforcer in the colony room for Group $F_{1} 180$; a 90 -sec access to the reinforcer in the colony room, then a 90 -sec exposure to background stimuli in the experimental room for Group F\&R; and a

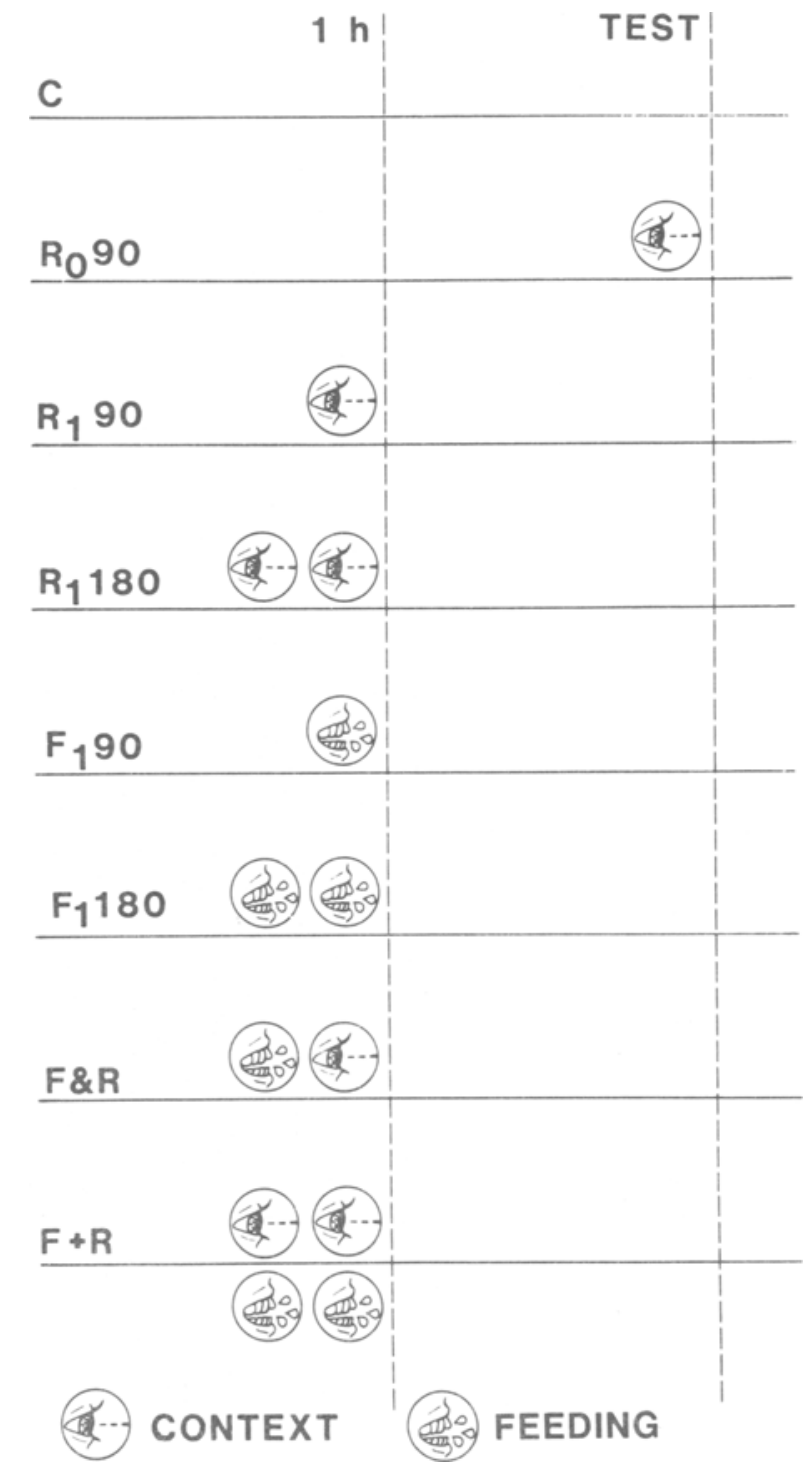

Figure 1. Experimental design at testing. Two groups were given either no treatment (Group C) or a pretest exposure to background stimuli in the experimental room (Group $\mathbf{R}_{0} 90$ ). The remaining groups were submitted to pretest treatments $1 \mathrm{~h}$ prior to testing, and spent the treatment-test interval in home cages. $C=$ control; $R=$ contextual cuing reminder treatment; $F=$ food availability; $F \& R=$ successive exposure to $F$ and $R ; F+R=$ simultaneous exposure to $F$ and $R$.

180-sec access to the reinforcer in the experimental room for Group $F+R$.

These treatments were given in the "reminder cages," which were identical to the home cages but equipped with a Plexiglas floor. One of these cages was located in the colony room (as in the pilot experiment); the other was located in the experimental room, close to the startbox of the maze. Since some animals had to be manipulated in the course of the pretest treatment (passage from the colony room to the experimental room in Group F\&R), animals in the other groups submitted to a 180-sec treatment (Groups $R_{1} 180, F_{1} 180$, and $F+R$ ) were likewise manipulated after $90 \mathrm{sec}$; the animals in these groups were removed from the reminder cage for approxi- 
mately $5 \mathrm{sec}$ and then immediately replaced into it. The animals submitted to a 90-sec treatment were not manipulated during this treatment.

This experiment was run twice. Statistical comparisons showed no difference between these replications, either in acquisition or in retention performance, so the data were pooled for subsequent analyses.

\section{Initial Training}

\section{Results}

As in previous experiments, the animals exhibited performance improvements on all indices. For example, mean error scores dropped from 5.2 (range: 4.7 to 5.5 ) on the first training trial to approximately 1.9 in each group on the last two training trials (see Figure 2, acquisition trials 4 and 5).

\section{Test: Within-Group Comparisons}

Run times. Animals assigned to the nonmanipulated control group (C) exhibited a large performance decrement at testing. Within-group comparison showed that this forgetting was highly significant $[F(1,13)=43.16, p<$ $.005]$.

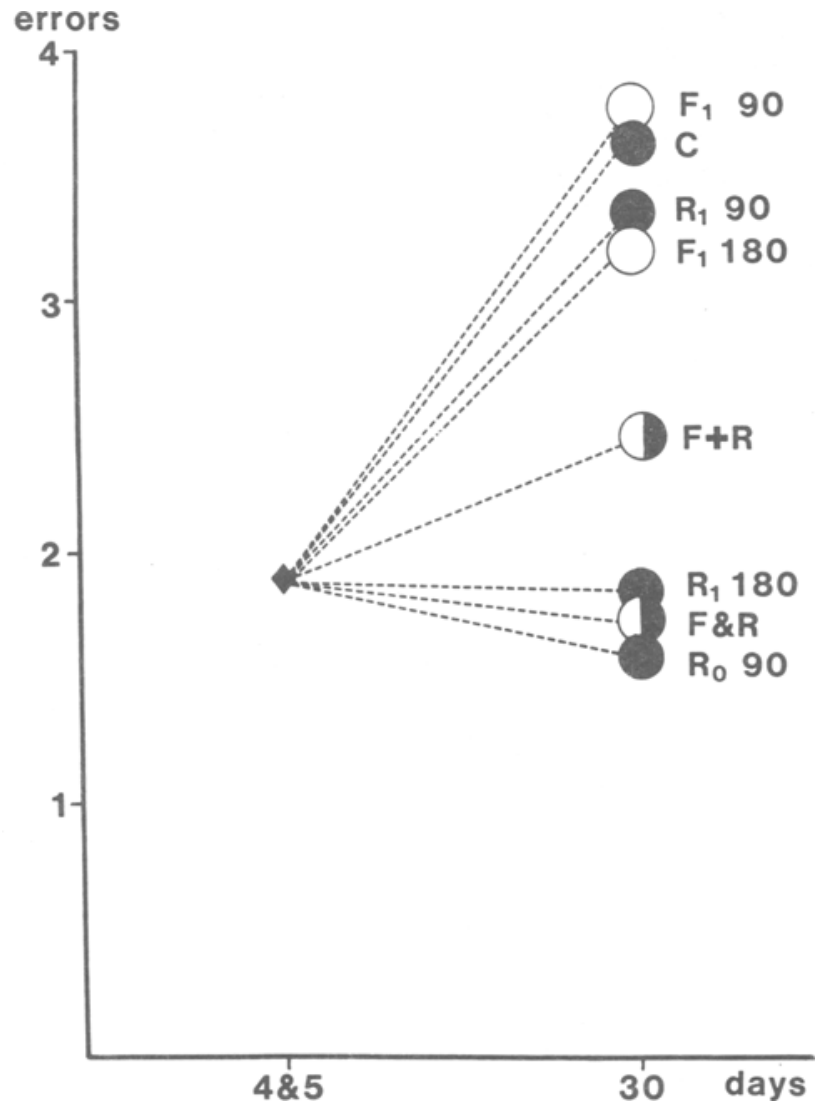

Figure 2. Error scores for combined groups at the end of training (4\&5, left; range: $1.89-1.96)$ and for individual groups at testing. Note the large performance decrement in Group $C$, the lack of effect of pretest treatments in $R_{1} 90, F_{1} 90$, and $F_{1} 180$, and the facilitation of performance in the four remaining groups. See text for statistical analysis.
As in several previous experiments, animals exposed to the experimental context $(90 \mathrm{sec}$, immediately prior to testing) did not show such a performance decrement $[F(1,13)=2.7]$

Among groups reminded $1 \mathrm{~h}$ before testing, the only one that showed no significant forgetting was Group $\mathrm{R}_{1} 180[F(1,13)=2.71]$. This forgetting was highly significant in all of the remaining groups $[F \mathrm{~s}(1,13)=21.22$ in Group $R_{1} 90,34.46$ in Group $F_{1} 90,14.2$ in Group $F_{1} 180,25.68$ in Group $F \& R, 43.15$ in Group $F+R$; all $p \mathrm{~s}<.005$ ].

Number of retracings. At testing, animals in Group C showed a significant increase in the number of retracings, relative to that at the end of training $[F(1,13)=6.83$, $p<.05$ ]

Animals in Group $R_{0} 90$ did not show any significant performance decrement as measured by retracings $[F(1,13)=1.23]$. Among groups submitted to a reminder treatment $1 \mathrm{~h}$ before testing, a significant performance decrement was observed only in Group $F_{1} 90[F(1,13)=$ $5.45, p<.05]$.

Error scores. At testing, control animals showed a highly significant performance decrement $[F(1,13)=$ $32.13, p<.005]$. On the other hand, as in several previous experiments, animals in Group $\mathrm{R}_{0} 90$ did not show any forgetting $[F(1,13)=.22]$ (see Figure 2).

For animals reminded $1 \mathrm{~h}$ before testing, the data were as follows (see Figure 2): In groups exposed to background stimuli in the experimental room, a significant forgetting was observed in Group $R_{1} 90[F(1,13)=16.52$, $p<.005]$ but not in Group $\mathrm{R}_{1} 180[F(1,13)=.18]$. In groups given access to the reinforcer in the colony room, significant forgetting was evidenced in both Group $F_{1} 90$ $[F(1,13)=48.33, p<.005]$ and Group $F_{1} 180[F(1,13)$ $=6.34, p<.05]$. In groups submitted to both pretest reminders, either successively (F\&R) or simultaneously (F+R), no significant forgetting could be detected $[F(1,13)=1.45$ and 2.52 , respectively $]$.

Individual test performance was classified into three categories, which corresponded to an increase, no difference, or a decrease in the number of errors relative to that obtained at the end of training (see Figure 3). This classification revealed dramatic forgetting in control animals. The chi-square (calculated without correction) revealed a significant difference among groups $\left[\chi^{2}(14)=\right.$ $33.17, p<.005]$. In Groups $F_{1} 90, F_{1} 180$, and $R_{1} 90$, this forgetting did not significantly differ from that of controls. In Groups $R_{0} 90, R_{1} 180, F+R$, and $F \& R$, however, it did.

\section{Test: Between-Group Analyses}

Run times. The analysis of variance performed on run times at testing revealed significant differences among groups $[F(7,104)=4.24, p<.005]$. Planned comparisons between control and treated groups showed or confirmed that 90 -sec pretest contextual cuing given immediately prior to testing alleviated forgetting [Group $\mathrm{C}$ vs. 


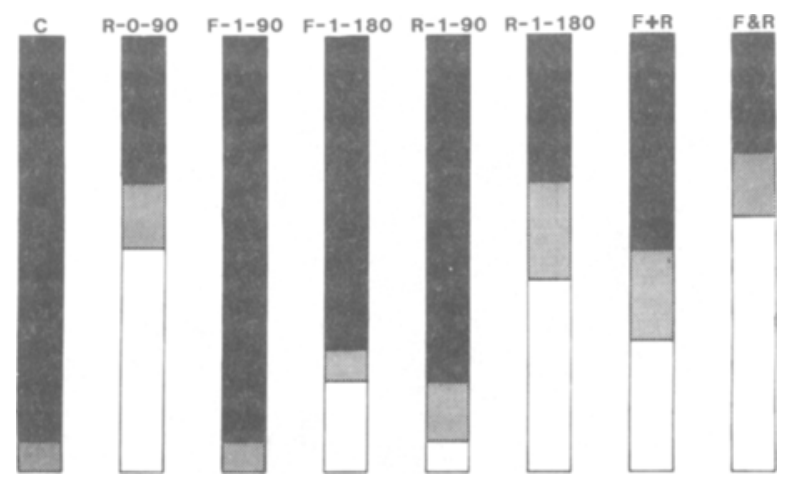

Figure 3. Classification of individual performance at testing, according to whether the animals made more errors (black), the same number of errors (gray), or fewer errors (white) than at the end of training. See text.

Group $\left.\mathrm{R}_{0} 90, F(1,111)=8.93, p<.01\right]$; that the same treatment given $1 \mathrm{~h}$ before testing had no significant effect [comparison of Groups $C$ and $R_{1} 90, F(1,111)=1.1$ ], but that lengthening this treatment up to $180 \mathrm{sec}$ did alleviate forgetting $[F(1,111)=8.9, p<.01]$; and that a pretest access to the reinforcer in the colony room for either 90 or $180 \mathrm{sec}$ had no significant effect $[F(1,111)$ $=.04$ and 1.71 , respectively] .

Number of retracings. The same analysis of variance revealed a significant difference in number of retracings among groups $[F(7,104)=3.08, p<.01]$. Planned individual comparisons showed that pretest contextual cuing, given either immediately prior to testing or $1 \mathrm{~h}$ before, always resulted in a significant reduction of retracings, as compared with those of control animals [for Group $\mathrm{R}_{0} 90, F(1,111)=9.78, p<.005$; for Group $\mathrm{R}_{1} 90, F(1,111)=5.42, p<.05$; and for Group $\mathrm{R}_{1} 180$, $F(1,111)=9.19, p<.005]$; that pretest access to the reinforcer in the colony room had no effect on test performance when given for $90 \mathrm{sec}[F(1,111)=.12]$, but did reduce the number of retracings when given for $180 \sec [F(1,111)=5.99, p<.01]$; and that the successive exposure to food in the colony room and to the experimental context had a significant facilitative effect $[F(1,111)=5.43, p<.05]$, although no effect could be detected in Group F+R.

Error scores. The analysis of variance performed on error scores at testing revealed a significant difference among groups $[F(7,104)=7.76, p<.005]$. Beyond the consistently observed facilitation (see Deweer \& Sara, 1984; Deweer et al., 1980) in Group $R_{0} 90[F(1,111)=$ $12.36, p<.005$ ], individual comparisons showed that 90-sec contextual cuing given $1 \mathrm{~h}$ prior to testing had no significant effect $[F(1,111)=1.21$; see Deweer \& Sara, 1984, Experiment 1], but that the same treatment given for $180 \mathrm{sec}$ did facilitate performance $[F(1,111)=9.41$, $p<.005$ ] (see Figure 2); that pretest access to the reinforcer in the colony room for either 90 or $180 \mathrm{sec}$ had no significant effect on error scores $\left[F_{\mathrm{s}}(1,111)=.26\right.$ and 2.01, respectively] (see Figure 2); and that the succes- sive exposure to the reinforcer and to the experimental context (Group F\&R) had facilitative effects on retention performance $[F(1,111)=16.73, p<.005]$. The simultaneous presentation of these two reminder treatments had the same kind of effect; however, the difference with control animals did not reach the .05 significance level $[F(1,111)=3.37, .10<p<.05]$.

Beyond these comparisons between reminded and control groups, we performed additional comparisons on Groups $F_{1} 90$ and $R_{1} 90$ and Groups F\&R and F+R. These comparisons revealed that animals successively submitted, $1 \mathrm{~h}$ prior to testing, to a 90-sec access to the reinforcer in the colony room, then to $90 \mathrm{sec}$ of contextual cuing (Group F\&R) were significantly better than animals given only access to the reinforcer in the colony room [Group $F_{1} 90, F(1,111)=8.95, p<.005$ ] and animals given only contextual cuing [Group $\mathrm{R}_{1} 90, F(1,111)=$ $21.23, p<.005$ ]; that performance of Group $F+R$ (simultaneous access to food and to the experimental context $1 \mathrm{~h}$ prior to testing) was also significantly better than that of animals in Group $N_{1} 90[F(1,111)=5.49, p<$ $.025]$ but did not significantly differ from that of animals in Group $R_{1} 90$; and that animals in Group F\&R made significantly fewer errors than did animals in Group $F+R$ $[F(1,111)=5.08, p<.05]$.

\section{DISCUSSION}

\section{Effects of Pretest Access to the Reinforcer}

In fact, the results of this experiment confirmed that a 90-sec pretest access to the reinforcer in the colony room $1 \mathrm{~h}$ prior to testing had no significant facilitative effect on retention performance. Animals in this condition showed significant forgetting, whatever the retention index (within-group comparisons); their performance did not differ from that of control animals (between-group comparisons). The individual evolution of performance between the end of training and testing was, strictly speaking, identical in these two groups (see Figure 3).

It is worth noting that this experiment demonstrated, moreover, that a longer access to the reinforcer in the colony room $1 \mathrm{~h}$ before testing was still rather ineffective. Although these animals made fewer retracings than controls at testing, no significant effect could be detected, either in terms of run times or in terms of error scores.

Thus, it seems reasonable to conclude that, in the present experimental conditions, pretest access to the specific reinforcer, whatever its duration, has no facilitative effect on retention performance $1 \mathrm{~h}$ later (see Moye \& Thomas, 1982, for a similar conclusion, in very different conditions and with "warm-up" treatments, in the pigeon).

Such a conclusion is not in agreement with some other data in the literature, which show that the presentation of the reinforcer constitutes one of the most efficient reminder treatments (see, e.g., Klein \& Spear, 1970; Lewis, 1969, 1976; Miller \& Springer, 1973, 1974; Spear \& Parsons, 1976). It must be first noted, however, that 
this reinforcer is typically aversive (in most cases, a noncontingent footshock; but see, e.g., Riccio \& Ebner, 1981, concerning hypothermia). The effects of the presentation of a positive reinforcer are not yet well known. It is true that Miller et al. (1974) showed that this kind of treatment could be efficient in reactivating memory; however, as noted by Moye and Thomas (1982), the complexity and the precise characteristics of the situation might play a crucial role in determining this effectiveness. It must also be noted that, while data obtained within reactivation paradigms (see Spear, 1978) are relatively consistent, the configuration is different in reinstatement paradigms (involving repeated presentations of reminder treatments during the retention interval). For example, although Silvestri, Rohrbaugh, and Riccio (1970) showed that the retention of a conditioned fear was a function of the duration of repeated presentations of the CS, they noted, at the same time, that presentations of the US were ineffective, whatever its duration. Finally, Campbell and Randall (1976), on the basis of their own data and other experiments (e.g., Greenfield \& Riccio, 1972), hypothesized that the effectiveness of reinstatement treatments could well be different depending on whether the initial training was appetitive or aversive. Our own data, obtained with a reactivation procedure, are not inconsistent with such a view.

Another explanation of the failure to obtain reactivation with pretest food presentation cannot be excluded, however. In our spontaneous paradigm, some type of food presentations (US) necessarily occurred during the retention interval, which might have led to some extinction of associations between food and maze running. By the same token, repeated exposures to the experimental room during the retention interval can also lead to an extinction of the cue value of this context (see Deweer et al., 1980).

\section{Effects of Pretest Contextual Cuing}

The results of this experiment confirmed those of several previous ones. They showed, one more time, that pretest contextual cuing, consisting of a 90 -sec exposure to background stimuli in the experimental room immediately prior to testing, alleviated spontaneous forgetting.

Furthermore, 90 -sec contextual cuing given $1 \mathrm{~h}$ prior to testing proved to have a very limited effect on retention performance, which confirms previously reported results (Deweer \& Sara, 1984, Experiment 1). In that experiment, animals in this condition showed important performance decrements, either in terms of run times or in terms of errors. They did not differ from control animals, except for retracings.

These results are also consistent with those of Deweer and Sara's (1984) Experiment 2, in that they confirm that the duration of contextual cuing might be a major determinant of retention performance. Although such a treatment, given for $90 \mathrm{sec}$, had no effect $1 \mathrm{~h}$ later, it was effective in alleviating forgetting when it was lengthened to $180 \mathrm{sec}$. At the same time, these data provide an answer to the question raised in Deweer and Sara's (1984) discussion: in our usual experimental conditions, temporal contiguity between contextual cuing and testing is not necessary for the facilitation of test performance (see also Dekeyne et al., in press).

It is more than likely that contextual cuing, whatever its duration (90 or $180 \mathrm{sec}$ ), reactivates memory of previous experiences in this context. This is attested to by the effects of immediate pretest cuing, in the present experiment as well as in several previous ones. However, a 90sec treatment had no detectable effect on test performance $1 \mathrm{~h}$ later. Lengthening it to $180 \mathrm{sec}$ did alleviate forgetting.

This difference may tentatively be accounted for in two different ways. First, it might be postulated that, although the memory of initial training was reactivated when the animals were placed in the experimental context, it became deactivated when they were carried back to the home cage. If, as proposed by Spear (1978) and Lewis (1979), any reactivation triggers a treatment of information in memory, making the target memory more easily accessible, it might be assumed that this treatment is more complete, or more elaborate, after a 180 -sec cuing episode than after a 90-sec one. Only the former would enhance retention performance $1 \mathrm{~h}$ later. The alternative consists of maintaining that lengthening the cuing episode triggers a more durable reactivation of the memory. In both groups, this memory would still be in an active state after the cuing episode, but a $90-\mathrm{sec}$ cuing would not be sufficient to reactivate the memory for $1 \mathrm{~h}$.

It is worth noting that, although the duration of a cuing episode can be a major determinant of retention performance (as is the case with contextual cuing), increasing the duration of any pretest cuing does not ipso facto modify its efficacy. Thus, pretest access to the reinforcer in the colony room $1 \mathrm{~h}$ prior to testing had no detectable effect regardless of its duration $(90$ or $180 \mathrm{sec})$. In other words, it is the nature of the information presented during cuing, and its relevance to previous experiences, which determines the reactivation of memories. Insofar as this information is really relevant, any modification of the duration of the cuing episode would modulate the efficacy of this reactivation.

\section{Effects of Successive or Simultaneous \\ Pretest Cuing Treatments}

Comparison of these effects. As mentioned in the introduction, this experiment was aimed at testing the general hypothesis that the probability of correct retention performance would be a function of the number (or kind) of events noticed during pretest cuing. That is why, along with a comparison of the effects of pretest exposure to the experimental context and pretest access to the reinforcer in the colony room, we studied two additional conditions in which animals were submitted to the two treatments, either successively or simultaneously.

The results showed that retention performance was rather good in these two conditions, in that no significant forgetting could be evidenced at testing (see Figure 3), and animals in Groups $F \& R$ and $F+R$ performed better 
than control animals. However, the effects of successive or simultaneous presentations of these two reminder treatments cannot be considered as identical. First, animals in Group F\&R (successive reminder treatments) were significantly better than controls at testing, but animals in Group F+R (concurrent reminder treatments) were not. Second, animals in Group F\&R were significantly better than animals in Group $\mathbf{F}+\mathbf{R}$ at testing (error scores).

It is somewhat difficult to account for this difference. Some behavioral observations, especially the number of rearings observed during the cuing episode, might nevertheless be relevant and useful. We noted that, although all animals submitted to a 180-sec treatment had been manipulated after $90 \mathrm{sec}$, this manipulation had different consequences among the groups. For animals in Group $F+R$, this manipulation consisted of removing them from the reminder cage for $5 \mathrm{sec}$ and then replacing them in it. This triggered a rebound in active exploration of the reminder cage (and, presumably, in visual exploration of the environment). But this rebound was short-lived (about $15 \mathrm{sec}$ ); afterwards there was still some rearing, although it became more and more spaced (along with a rebound in feeding behavior, which may have competed for the necessary attention to the other contextual cues in the training environment). On the other hand, for animals in Group F\&R, the manipulation consisted of passage from the reminder cage in the colony room (with food) to the reminder cage in the experimental room (without food, which precludes any competition between eating behavior and attention to distal cues in the environment). This triggered a more pronounced and much more durable rebound in number of rearings (and, presumably, in visual exploration of the proximal and distal environments; Platel, 1978). It can be hypothesized that these different behavioral consequences of manipulation during cuing were correlated with some differences in perception and/or treatment of the experimental context.

Synergistic properties of reminder combinations. These data showed that animals given access to the reinforcer in the colony room for $90 \mathrm{sec}$ and then receiving 90-sec contextual cuing in the experimental room (Group F\&R) did not show any forgetting $1 \mathrm{~h}$ later. These animals were significantly better not only than control animals, but also than animals in Groups $F_{1} 90$ and $R_{1} 90$. In other words, the successive exposure to two reminder treatments, which, when given alone, could not alleviate spontaneous forgetting, led, $1 \mathrm{~h}$ later, to a very important enhancement of retention performance.

The same kind of synergy between pretest feeding and pretest contextual cuing was also evidenced, to a lesser degree, in Group $F+R$. We noted that animals in this group performed significantly better than animals only given access to food, although it must be acknowledged, at the same time, that they did not perform significantly better than animals subjected only to pretest contextual cuing. It can be maintained, nevertheless, that the main evidence is that animals in Groups $F_{1} 90$ and $R_{1} 90$ forgot, whereas animals in Group $F+R$ did not.
It seems very difficult to account for this configuration of the data in terms of duration of pretest cuing treatments. It could be assumed that longer treatments (180 sec, as for Groups F\&R and F+R) would allow a more elaborate integration of current information and memories-that is, better retrieval-than shorter ones (as for Groups $F_{1} 90$ and $N_{1} 90$ ). However, such a hypothesis is not consistent with some other data in this experiment. As noted earlier, increasing the duration of any pretest cuing treatment alone does not necessarily result in enhancing the efficacy of this treatment.

It is more likely the nature of pretest cuing treatments which could account for the differences observed at testing. In fact, all reminder treatments that alleviated spontaneous forgetting involved an exposure to background stimuli in the experimental room (Groups $R_{0} 90, R_{1} 180$, $F \& R$, and $F+R)$. Although this condition is not always sufficient (see Group R,90 and also Deweer \& Sara, 1984, Experiment 2), it does seem to be necessary here. The question of the crucial role played by the experimental context in our paradigm is more directly addressed in another paper (Deweer, 1986). It can nevertheless be noted here that this paradigm particularly underlines the role of context: (1) The task implies, much more than (for example) active or passive avoidance learning, that animals take into account some spatial landmarks; and (2) throughout both pretraining and training, background stimuli in the experimental room are always associated with the reinforcer.

It seems possible, in the same way, to account for the lack of effectiveness of pretest feeding in the colony room. In our view, this treatment is not really a reminder treatment (Deweer, 1985), insofar as we consider a reminder treatment in animal studies as equivalent to pretest instructions in human studies (Deweer, 1986). Although it obviously allows access to the specific reinforcer used during pretraining and training, it is, at the same time, a new experience, possibly interacting with previous experiences in a different context. More precisely, we would propose that pretest feeding in the colony room can reactivate only some of the attributes that are common to the two representational networks respectively refering to pretraining and training (which share some common characteristics, but at the same time are very different experiences), whereas another pretest treatment, contextual cuing, can trigger a differential reactivation of these two networks, that is, can act as a pretest instruction.

\section{REFERENCES}

Asratian, E. A. (1965). The initiation and localization of cortical inhibition in the conditioned reflex arc. Annals of the New York Academy of Sciences, 92, 1141-1159.

Bower, J. H. (1967). A multi-component theory of the memory trace. In K. W. Spence \& J. T. Spence (Eds.), The psychology of learning and motivation (Vol. 1). New York: Academic Press.

Campbell, B. A., \& Randall, P. K. (1976). The effect of reinstatement stimulus condition on the maintenance of long-term memory. Developmental Psychobiology, 9, 325-334. 
CAPALDI, E. J. (1971). Memory and learning: A sequential viewpoint. In W. H. Honig \& P. H. R. James (Eds.), Animal memory. New York: Academic Press.

DekeYNe, A., Deweer, B., \& SARA, S. J. (in press). Background stimuli as a reminder after spontaneous forgetting: Potentiation by MRF stimulation. Behavioral Brain Research. (Abstract)

DEWEER, B. (1985). Contexte et oubli: Contribution à l'étude de l'évocation mnesique chez l'animal. Unpublished doctoral dissertation, Universite Paris Sud.

DEWEER, B. (1986). Contextual cue reminders as pretest instructions for rats. Manuscript submitted for publication.

DEWEER, B., \& SARA, S. J. (1984). Backgl uund stimuli as a reminder after spontaneous forgetting: Role of duration of cuing and cuing-test interval. Animal Learning \& Behavior, 12, 238-247.

DEWEER, B., \& SARA, S. J. (1985). Alleviation of forgetting by pretest contextual cueing in rats. In D. Olton, E. Gamzu, \& S. Corkin (Eds.) Memory dysfunctions: An integration of animal and human research from preclinical and clinical perspectives. Annals of the New York Academy of Sciences, 444, 507-509.

Deweer, B., Sara, S. J., \& Hars, B. (1980). Contextual cues and memory retrieval in rats: Alleviation of forgetting by a pretest exposure to background stimuli. Animal Learning \& Behavior, 8 , 265-272.

GATTI, S. V., PAIS, N., \& WEEKS, J. R. (1975). Effect of reinstatement procedure on retention of differential appetitive responding. Bulletin of the Psychonomic Society, 6, 57-60.

GorDON, W. C. (1981). Mechanisms of cue-induced retention enhancement. In N. E. Spear \& R. R. Miller (Eds.), Information processing in animals: Memory mechanisms. Hillsdale, NJ: Erlbaum.

Greenfield, A. , \& Riccio, D. C. (1972). Conditioned reinstatement in rats: Effects of exposure distribution and cue. Psychological Reports, 31, 79-83.

Hickis, C. F., Robles, L., \& Thomas, D. R. (1977). Contextual stimuli and memory retrieval in pigeons. Animal Learning \& Behavior, 5 , 161-168.

Holloway, F. A. (1978). State dependent retrieval based on time of day. In B. Y. Ho, D. W. Richards, D. L. Chute (Eds.), Drug discrimination and state dependent learning. New York: Academic Press.

Holloway, F. A., \& W ANSLEY, R. A. (1973). Multiple retention deficits at periodic intervals after passive avoidance learning. Science, $\mathbf{8 0}$, 208-210.

KleIN, S. B., \& SPEAR, N. E. (1970). Forgetting by the rat after intermediate intervals ("Kamin effect") as retrieval failure. Journal of Comparative \& Physiological Psychology, 71, 165-170.

LEWIS, D. J. (1969). Sources of experimental amnesia. Psychological Review, 76, 461-472.

LEWIS, D. J. (1976). A cognitive approach to experimental amnesia. American Journal of Psychology, 89, 51-80.

LEWIS, D. J. (1979). Psychobiology of active and inactive memory. Psychological Bulletin, 86, 1054-1083.

Lewis, D. J., Misanin, J. R., \& Miller, R. R. (1968). Recovery of memory following amnesia. Nature, 220, 704-705.

MCAllister, W. R., \& MCAllister, D. E. (1971). Behavioral measurement of conditioned fear. In F. R. Brush (Ed.), Aversive conditioning and learning. New York: Academic Press.
Miller, R. R., Ott, C. A., Berk, A. M. \& Springer, A. D. (1974) Appetitive memory restoration after electroconvulsive shock in the rat. Journal of Comparative \& Physiological Psychology, 87, 717-723.

Miller, R. R., \& SPRINGER, A. D. (1972). Induced recovery of memory in rats following electroconvulsive shock. Physiology \& Behavior, 8, 645-651.

Miller, R. R., \& Springer, A. D. (1973). Amnesia, consolidation and retrieval. Psychological Review, 80, 69-79.

MilleR, R. R., \& SpRINGeR, A. D. (1974). Implications of recovery from experimental amnesia. Psychological Review, 81, 470-473.

MoYe, T. B., \& ThомAs, D. R. (1982). Effects of memory reactivation treatments on postdiscrimination generalization performance in pigeons. Animal Learning \& Behavior, 10, 159-166.

Perkins, C. C. \& Weyant, R. G. (1958). The interval between training and test trials as determiner of the slope of generalization gradients. Journal of Comparative \& Physiological Psychology, 51, 596-600.

Platel, A. (1978). Étude d'un modele d'apprentissage: Lhabituation à un environment chez le rat. Ses lois temporelles et leur modification par stimulation cérébrale. Unpublished Thèse de 3 eme cycle, Université Paris Sud.

RICCIO, D. C., \& EBNER, D. L. (1981). Postacquisition modification of memory. In N. E. Spear \& R. R. Miller (Eds.), Information processing in animals: Memory mechanisms. Hillsdale, NJ: Erlbaum.

Riccio, D. C., URDA, M., \& Thomas, D. R. (1966). Stimulus control in pigeons based on proprioceptive stimuli from the floor inclination. Science, 153, 434-436.

Sara, S. J., David-Remacle, M., \& Lefevre, D. (1975). Passive avoidance behavior in rats after electroconvulsive shock: Facilitative effects of response retardation. Journal of Comparative \& Physiological Psychology, 89, 489-497.

Sara, S. J., Deweer, B., \& Hars, B. (1976). Forgetting as a lapse, not a loss: Facilitation of retrieval by a reminder. Bulletin de la Société Belge de Psychologie, 2, 23-24.

Silvestri, R., Rohrbaugh, M. J., Riccio, D. C. (1970). Conditions influencing the retention of learned fear in young rats. Developmental Psychology, 2, 380-395.

Spear, N. E. (1967). Retention of reinforcer magnitude. Psychological Review, 74, 216-234.

SPEAR, N. E. (1978). The processing of memories: Forgetting and retention. Hillsdale, NJ: Erlbaum.

Spear, N. E., \& Parsons, P. (1976). Analysis of a reactivation treatment: Ontogeny and alleviated forgetting. In D. Medin, R. Davies, \& W. Roberts (Eds.), Coding processes in animal memory. Hillsdale, NJ: Erlbaum.

STEINMAN, F. (1967). Retention of alley brightness in the rat. Journal of Comparative \& Physiological Psychology, 64, 105-109.

Tномаs, D. R. (1981). Studies of long-term memory in the pigeon. In N. E. Spear \& R. R. Miller (Eds.), Information processing in animals: Memory mechanisms. Hillsdale, NJ: Erlbaum.

Tulving, E., \& THOMSON, D. (1973). Encoding specificity and retrieva processes in episodic memory. Psychological Review, 80, 352-373.

(Manuscript received February 4, 1986; revision accepted for publication June $10,1986$. 